\title{
Saberes e Modos de Vida \\ Por um Projeto Coletivo de Turismo de Base Comunitária na Comunidade Ribeirinha São Gonçalo Beira Rio, Mato Grosso, Brasil
}

\author{
http://dx.doi.org/10.21527/2237-6453.2020.53.202-221
}

Recebido em: $11 / 3 / 2020$

Aceito em: 18/8/2020

Liliane Cristine Schlemer Alcântara, ${ }^{1}$ Ana Paula Pereira Duarte ${ }^{2}$

\begin{abstract}
RESUMO
Diante da crise socioeconômica e ambiental, o Turismo de Base Comunitária (TBC) representa uma alternativa ao desenvolvimento que tem como escopo conservar os recursos naturais, promovendo o bem-estar das comunidades por meio da geração de renda e inclusão social. O objetivo deste estudo está em investigar os principais desafios e possibilidades para o desenvolvimento do Turismo de Base Comunitária na comunidade ribeirinha São Gonçalo Beira Rio, marco da fundação do município de Cuiabá-MT. Metodologicamente optou-se pela pesquisa de campo; como ferramenta de análise situacional, a matriz de Swot e a análise dos dados foram concatenados com o discurso de Foucault. Os resultados preliminares evidenciam que a localidade de São Gonçalo Beira Rio apresenta possibilidades para o desenvolvimento do TBC, em razão da riqueza de saberes e dos modos de vida desta comunidade. Em função, porém, da complexidade e das inúmeras variáveis identificadas, será necessário um planejamento coletivo, iniciando-se pela sensibilização, mobilização e qualificação dos atores envolvidos, bem como adoção de estratégias comunitárias a fim de auferir melhores resultados.
\end{abstract}

Palavras-chave: Turismo de base comunitária. Planejamento estratégico. Estudo diagnóstico. Comunidade local.

\section{KNOWLEDGE AND MODES OF LIFE: FOR A COMMUNITY-BASED TOURISM PROJECT IN THE RIVERSIDE COMMUNITY SÃO GONÇALO BEIRA RIO, MATO GROSSO, BRAZIL}

\section{ABSTRACT}

Facing the socioeconomic and environmental crisis, community-based tourism (TBC) represents an alternative to development that aims to conserve natural resources, promoting the well being of communities through income generation and social inclusion. The objective of this study is to investigate the main challenges and possibilities for the development of community-based tourism in the São Gonçalo Beira Rio riverside community, a landmark in the city of Cuiabá-MT. Methodologically, we opted for field research; as a situational analysis tool, the Swot matrix and Foucault's discourse analysis. The preliminary results lead us to believe that the locality of São Gonçalo Beira Rio presents possibilities for the development of TBC, as opposed to the wealth of knowledge and ways of life of this community. However, due to the complexity and the many variables identified, collective planning will be necessary, starting with the sensitization, mobilization and qualification of the actors involved, as well as adoption of strategies community involvement in order to obtain better results.

Keywords: Community-based tourism. Strategic planning. Diagnostic study. Local community.

\footnotetext{
${ }^{1}$ Doutora em Desenvolvimento Regional pela Universidade Regional de Blumenau (Furb). Professora da Faculdade de Administração e Ciências Contábeis (Facc) da Universidade Federal de Mato Grosso (UFMT) e do Programa de Pós-Graduação em Ciências Ambientais (PPGCA) da Universidade do Estado de Mato Grosso (Unemat). http://lattes.cnpq.br/5051941963927036. https://orcid.org/0000-00018502-720X. lilianecsa@yahoo.com.br

${ }^{2}$ Mestre em Nutrição, Alimentos e Metabolismo pela Universidade Federal de Mato Grosso (UFMT). http://lattes.cnpq.br/5167863830087714. http://orcid.org/0000-0003-1239-0248. ana.ppd@hotmail.com
} 
No Brasil a atividade turística é reconhecida como um importante gerador de divisas, de oportunidade de trabalho e renda, contribuindo para minimizar as desigualdades regionais e sociais (BARTHOLO; SANSOLO; BURSZTYN, 2009). Isso é possível em decorrência da ampla diversidade cultural e das inúmeras belezas naturais dispersas por todo o território nacional.

A relação sinérgica do homem com a cultura e natureza pode tornar-se uma importante fonte de lazer e entretenimento, fomentando o desenvolvimento local e a inclusão social. Esse relacionamento harmônico possibilita o desenvolvimento do Turismo de Base Comunitária (TBC), que cada vez mais representa uma atividade alicerçada nos princípios da economia solidária, associativismo e valorização da cultura, constituindo o protagonista principal das comunidades locais (FREIRE; FERREIRA, 2015; FABRINO; NASCIMENTO; COSTA, 2016).

O Turismo de Base Comunitária caracteriza-se por promover um menor impacto à natureza, revelando-se atualmente uma atividade desenvolvida em várias localidades do país, como: Turismo de Base Comunitária Acolhida na Colônia em Santa Rosa de Lima, em Santa Catarina (GUZZATTI; SAMPAIO; CORIOLANO, 2013); Núcleo de Turismo de Base Comunitária do Boné na Serra do Brigadeiro, em Minas Gerais (MORAES; EMMENDOERFER, 2015); Ilha de Marajó, Santarém e Curuçá, no Pará (FREIRE; FERREIRA, 2015); Quilombo Cabula, na Bahia (SILVA; MATTA; SÁ, 2016); Projeto da Rede Tucum, comunidades de Batoque, Balbino, Jenipapo, Kanidé e Ponta Grossa, no Ceará (GABRIELL; SANTOS, 2016; GÓMEZ et al., 2016; LOBO, 2017); TBC na Reserva de Desenvolvimento Sustentável Ponta do Tubarão, no Rio Grande do Norte (GONÇALVES; SILVA, 2017), entre outras experiências exitosas.

No Estado de Mato Grosso, rico em diversos biomas (Pantanal, Cerrado e a Amazônia), a atividade turística é um segmento forte da economia local. Essa diversidade permite o desenvolvimento de várias modalidades de turismo, entre as quais ecológico, de aventura e pesca esportiva ${ }^{3}$ (MATO GROSSO, 2018). A capital mato-grossense, Cuiabá, também apresenta elevada potencialidade turística, resultante dos inúmeros aspectos culturais, tais como manifestações folclóricas e religiosas, artesanato e culinária tradicional, elementos que podem enriquecer a experiência turística.

No Brasil, as primeiras experiências de TBC datam de meados da década de 90 e foram organizadas independentemente de ações públicas. Como política pública, do Ministério do Turismo, o TBC iniciou-se a partir de 2007 pelo Plano Nacional de Turismo (BRASIL, 2010a), no entanto até o presente, em Cuiabá não há ações governamentais e/ ou privadas nesse segmento. A escassez de relatos da prática de TBC na capital mato-grossense motivou o estudo da viabilidade socioeconômica e ambiental da instituição dessa atividade turística em uma comunidade ribeirinha tradicional da capital mato-grossense, a comunidade de São Gonçalo Beira Rio.

\footnotetext{
${ }^{3} \mathrm{O}$ turismo de aventura é a modalidade em que o turista protagoniza atividades de aventura, entendidas como experiências físicas, sensoriais e recreativas que envolvem prazer, liberdade e superação. $O$ turismo ecológico pressupõe atividades que promovem a reflexão e a integração entre homem e ambiente (MESQUITA, 2014). Já o turismo de pesca é conhecido como pesca esportiva sem fins lucrativos, quando se devolve o peixe ao rio.
} 
Essa localidade apresenta forte ligação com o meio urbano, representadas pelos fluxos de bens, pessoas, recursos naturais, capital, trabalho, serviços, informação e tecnologia. De acordo com IBGE (2017), os limites oficiais entre zona urbana e zona rural são em grande parte instrumentos definidos segundo objetivos fiscais, no entanto se considerarmos concentração ou a ocupação econômica da população (ENDLICH, 2010), a comunidade de São Gonçalo Beira Rio tem características socioespaciais de perspectiva rural.

São Gonçalo Beira Rio é um dos primeiros povoados do município, completou seu tricentenário em janeiro de 2018; localidade guardiã das tradições cuiabanas, como o cururu, o siriri, a viola de cocho, a culinária tradicional e o artesanato em cerâmica. Destaca-se por sua notável resistência em cultivar tradições culturais, mesmo estando tão próxima da modernidade urbana de uma capital.

Desta forma, o objetivo deste estudo está em investigar os principais desafios e possibilidades para o desenvolvimento do turismo de base comunitária na comunidade ribeirinha São Gonçalo Beira Rio, marco da fundação do município de Cuiabá-MT. Nesse sentido, o trabalho apresenta uma pesquisa exploratória-descritiva com abordagem qualitativa, em que a pesquisa, análise bibliográfica e documental teve como foco a busca de dados relativos ao turismo de base comunitária e historicidade da comunidade de São Gonçalo Beira Rio. O levantamento deu-se por meio de consulta em livros, artigos de periódicos científicos, dissertações e teses acadêmicas, sites institucionais, legislação e pesquisa "in loco" por meio de entrevistas e observação participante.

O artigo está estruturado em cinco seções além dessas notas introdutórias: na primeira, referencial teórico sobre turismo de base comunitária e atividade turística no Estado de Mato Grosso; na segunda, os procedimentos metodológicos; na terceira a contextualização e diagnóstico da comunidade ribeirinha São Gonçalo Beira Rio; na quarta, discussão e resultados do trabalho; na quinta seção, considerações finais desta pesquisa. Finaliza-se com as referências que embasaram este estudo.

\section{TURISMO DE BASE COMUNITÁRIA: GÊNESE DO CONCEITO}

O Turismo de Base Comunitária (TBC) ou Turismo Comunitário (TC) "é aquele desenvolvido pelos próprios moradores de um lugar, que passaram a ser os articuladores e os construtores da cadeia produtiva, onde a renda e o lucro ficam na comunidade e contribuem para a melhoria da qualidade de vida" (CORIOLANO, 2009, p. 282). Além disso, promove a revitalização econômica, estimula a valorização do patrimônio cultural, bem como da conservação e preservação ambiental, fatores que podem atrair investimentos públicos, nos locais em que esteja sendo desenvolvido (BRASIL, 2010b).

O TBC não é um segmento do turismo, mas sim uma metodologia de trabalho (TURISOL, 2018; MIELKE; PEGAS, 2013). De acordo com Sampaio et al. (2014), o turismo comunitário surgiu no Brasil em 1997, primeiramente como tema de diálogo científico no 10 Encontro Nacional de Turismo de Base Local, realizado em São Paulo. Posteriormente, adicionou-se ao debate acadêmico a participação de movimentos sociais durante a realização do 10 Seminário Internacional de Turismo Sustentável, promovido em Fortaleza no ano de 2003. Alguns anos mais tarde, com a temática mais consolidada, o Ministério do Turismo (MTur), na elaboração de Plano Nacional de Turismo 2007-2010, elencou ações para apoiar as iniciativas para o desenvolvimento de TBC (BRASIL, 2010a). 
O Plano Nacional de Turismo (PNT) atual, 2018-2022, tem por objetivos: contribuir para a redução das desigualdades sociais e econômicas regionais, promover a inclusão social pelo crescimento da oferta de trabalho e melhor distribuição de renda (BRASIL, 2018); e entre as inúmeras estratégias descritas no PNT, a de estimular o desenvolvimento de novas atividades turísticas que incorporem aspectos da produção local, da cultura e da culinária regional, podem favorecer as iniciativas de desenvolvimento do TBC.

O Ministério do Turismo, para desenhar sua política pública para o TBC, norteou-se no conceito preconizado pela Organização Não Governamental World Wide Fund for Nature (2018) como destaca Maldonado (2009, p. 31):

Turismo Comunitário é toda forma de organização empresarial sustentada na propriedade e na autogestão sustentável dos recursos patrimoniais comunitários, de acordo com as práticas de cooperação e equidade no trabalho e na distribuição dos benefícios gerados pela prestação dos serviços turísticos.

Outra característica marcante do TBC é a sua dimensão antropológica, com objetivo de estimular o diálogo entre iguais e encontros interculturais com os visitantes, na perspectiva de se conhecer e aprender com seus respectivos modos de vida (MALDONADO, 2009; BRAMBATTI; NITSCHE, 2018).

No Brasil o TBC surge como uma modalidade turística ascendente, sobretudo em áreas de relevância ambiental, que em sua maioria albergam comunidades com poucas perspectivas econômicas. O TBC é uma prática alternativa, que permite a manutenção do vínculo com o ambiente, mas também com a dimensão sociocultural, por meio do estímulo de trocas culturais entre visitantes e moradores, podendo igualmente apontar caminhos frutíferos para a melhoria da qualidade de vida e do bem-estar da população receptora (HALLACK; BURGOS; CARNEIRO, 2011; ALCÂNTARA; FEUSER; SAMPAIO, 2015). Para Grimm, Alcântara e Sampaio (2018, p. 10),

[...] uma das características básicas do turismo brasileiro é a diversidade e abundância de seus recursos, cuja exploração deu lugar ao desenvolvimento turístico diferenciado no tempo e espaço, e a criação de inúmeros produtos, onde se identificam regiões com intensidades turísticas desiguais e qualitativamente distintas.

Para Fabrino, Nascimento e Costa (2016), embora não haja unanimidade entre a comunidade científica para a definição de TBC, todos consideram como elemento fundamental a comunidade como sujeito de seu próprio avanço, participando da concepção, desenvolvimento e gestão do turismo. A terminologia TBC deriva de outras modalidades turísticas, conhecidas como turismo cultural ou etnoturismo, ecoturismo e agroturismo 4 (SAMPAIO et al., 2014) e, está fortemente associada ao turismo sustentável e ao desenvolvimento local (FABRINO; NASCIMENTO; COSTA, 2016). A acepção do

\footnotetext{
${ }^{4}$ O turismo cultural ou etnoturismo volta-se para a observação ou convívio de estilos de vida tradicionais (BARRETO, 2004). Fennell (2001, apud Weaver; Laton, 2007) identifica 85 definições de ecoturismo e seus valores estão baseados em conservação, ética, sustentabilidade, educação e benefícios comunitários. O agroturismo refere-se a um conjunto de serviços requeridos por visitantes e turistas que desejam adquirir a experiência de conhecer a vida de uma pequena propriedade rural (OYARZÚN; CARCAMO, 2001).
} 
planejamento do TBC necessita ser debatida à luz da teoria da participação social, do desenvolvimento comunitário, assim como do planejamento participativo (HALLACK; BURGOS; CARNEIRO, 2011; ALMEIDA; CASTRO, 2017).

O MTur, embora considere as especificidades de cada conceito empregado para TBC, elenca os princípios comuns a todos, destacando: autogestão; associativismo e cooperativismo; democratização de oportunidades e benefícios; centralidade da colaboração, parceria e participação; valorização da cultura local, visando à apropriação por parte destas dos benefícios advindos do desenvolvimento da atividade turística (BRASIL, 2010a).

No TBC a comunidade tem papel primordial e central, ela deve estar engajada no projeto e ações para o sucesso da atividade, pois esse tipo de turismo prima pelo reconhecimento e valorização do patrimônio comunitário, ou seja, do conjunto de valores e crenças, conhecimentos e práticas, técnicas e habilidades, instrumentos e artefatos, lugares e representações, bem como de todos os tipos de manifestações tangíveis e intangíveis existentes em um povo (BARTHOLO; SANSOLO; BURSZTYN, 2009).

Em 2010, a Rede Brasileira de Turismo Solidário e Comunitário - Turisol - publicou uma série denominada de Série Turisol de Metodologias no Turismo Comunitário, que registram sete histórias e metodologias de experiências com TBC: 1) Projeto Saúde e Alegria (Santarém, PA), 2) Associação de Agroturismo Acolhida na Colônia (SC), 3) Pousada Uacari, Instituto Mamirauá (Tefé, AM), 4) Projeto Bagagem (São Paulo, SP), 5) Fundação Casa Grande (Nova Olinda, CE), 6) Rede Tucum (12 comunidades do litoral do Ceará) e 7) Pousada Aldeia dos Lagos (Silves, AM). Com estes registros, a Rede Turisol visava a informar, compartilhar e inspirar o desenvolvimento de novas iniciativas voltadas ao Turismo Comunitário no Brasil e no mundo (TURISOL, 2018).

Além do envolvimento comunitário, outro aspecto que contribuiu para o fomento do TBC foi a transformação pela qual passou o fenômeno turístico com relação à pessoa do turista, que se converteu no ator principal da própria viagem, buscando a vivência de acontecimentos únicos e marcantes (PEZZI; VIANNA, 2015). Para Krippendorf (2000) as pessoas estão preocupadas em praticar um turismo mais consciente, deixando de ser um turista conduzido e manipulado para se tornar um turista informado e experiente. Na concepção antropológica, essa forma de fazer turismo trata-se da suspensão das relações cotidianas, a interrupção de papéis, em que o sujeito sofre um estranhamento em relação ao que lhe é familiar (TURNER; BRUNER, 1986).

Esse novo perfil possibilitou a inserção do turismo em localidades pitorescas, porém excluídas dos roteiros de visitação e não vistas como um atrativo turístico. Nesse contexto, localidades com um potencial turístico reprimido puderam se beneficiar com a instauração do turismo de base comunitária. Desta forma, o TBC oportuniza aos visitantes o contato com o modo de vida local, de maneira sustentável, permitindo tanto a preservação dos sistemas ecológicos como a conservação dos sistemas sociais, além de ser uma estratégia de comunicação social, mediante a qual as comunidades tradicionais ofertam como principal atrativo a convivencialidade (SAMPAIO et al., 2014). Esse convívio deve pautar-se no respeito à simplicidade da localidade, de suas rotinas, de seu linguajar e tradições, ou seja, de acordo com Bartholo, Sansolo e Bursztyn, (2009), na valorização do patrimônio comunitário (recursos humanos, culturais e naturais). 


\section{Atividade Turística em Mato Grosso}

De acordo com a Organização Mundial do Turismo (OMT), o setor turístico é a segunda maior atividade econômica do mundo em geração de divisas e empregos, pois possibilita o aproveitamento de características históricas, culturais, físicas, econômicas e sociais (WTO, 2018).

No Estado de Mato Grosso essa atividade também é representativa economicamente, pois a região é rica por sua variedade de biomas (Pantanal, Cerrado e Amazônia), fato que a torna atrativa para pessoas do mundo todo, além de possibilitar o desenvolvimento de várias modalidades de turismo, entre as quais o ecológico, o de aventura e pesca esportiva (MATO GROSSO, 2018). Em Mato Grosso podem ser encontrados bom exemplos de atrativos turísticos, embora pontuais, localizados em comunidades circunvizinhas à capital, como Chapada dos Guimarães, Cáceres, Bom Jardim (em Nobres), Santo Antônio do Leverger e outros em vários municípios do Estado. Essas regiões geralmente são priorizadas na destinação de projetos e ações de fortalecimento à indústria do turismo. Na capital mato-grossense, Cuiabá, mesmo com o forte potencial histórico, a atividade turística é pouco valorizada e explorada.

Atualmente Mato Grosso conta com uma Política Estadual do Turismo - Lei no 10.183 de 2014 - que tem por princípios a promoção da atividade turística sustentável, com preservação e conservação do meio ambiente, valorização da diversidade cultural, inclusão social e eficiência econômica; de modo a transformar o Estado em destino turístico diferenciado e competitivo, tanto para o mercado nacional quanto internacional (MATO GROSSO, 2014).

Para algumas localidades da capital de Mato Grosso, o TBC pode ser uma alternativa socioeconômica interessante em múltiplos aspectos, observando-se que o incentivo a essa prática constitui um dos objetivos preconizados na política mato-grossense de turismo, conforme consta no artigo 4 o inciso VIII: "fomentar a atividade turística em patrimônios naturais, histórico e cultural", entretanto na prática não existem ações concretas de incentivo a essa forma de se fazer turismo.

Além das riquezas naturais, o Estado mato-grossense conta ainda com vasto patrimônio histórico e áreas agrícolas que possibilitam o desenvolvimento do turismo cultural e rural; essas modalidades turísticas têm um grande potencial como agente promotor de desenvolvimento local, com geração de emprego e renda (FAGUNDES; SCHMIDT; CENTURIÃO, 2013) e não deveriam ser colocadas em um segundo plano e/ou ignoradas.

\section{PROCEDIMENTOS METODOLÓGICOS}

Na realização deste estudo foram desenvolvidas quatro etapas metodológicas: (1) pesquisa descritiva com revisão e análise bibliográfica e documental; (2) pesquisa de campo (entrevista estruturada e observações); (3) análise dos dados observados empregando a matriz de Swot e (4) análise das entrevistas utilizando a técnica de análise de discurso proposta por Michel Foucault (1969). Ao mesmo tempo, em razão das etapas metodológicas previstas, desenvolveu-se uma triangulação de dados, conforme mostra a Figura 1. 
O termo triangulação é baseado na técnica de determinação da localização de um navio no oceano por meio das posições de três estrelas no céu; porém, em se tratando de procedimento de pesquisa, o desafio principal do pesquisador não é localizar-se, mas conferir significado às suas conclusões (STAKE apud ZAPPELLINI; FEUERSCHÜTTE, 2015).

Figura 1 - Triangulação dos dados

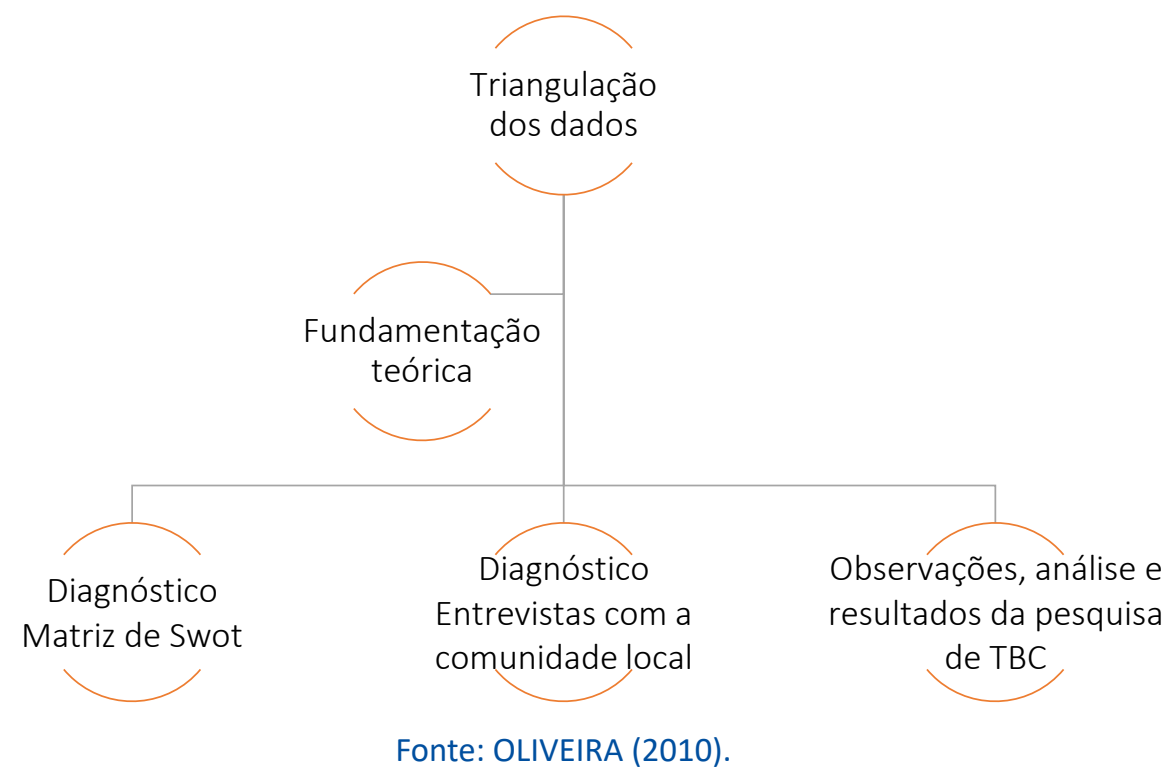

A triangulação foi aplicada para validação, pois nos permite analisar o fenômeno em estudo de diferentes formas e as evidências obtidas são consideradas fortes, pois se reduzem eventuais vieses no processo de coleta de dados (ZAPPELLINI; FEUERSCHÜTTE, 2015).

Desta forma, para atender aos objetivos propostos neste estudo, sumarizado no Quadro 1, utilizou-se a abordagem exploratória-descritiva, de caráter qualitativo, precedida de pesquisa e análise bibliográfica.

A pesquisa de campo foi realizada por meio da aplicação de seis entrevistas semiestruturadas gravadas com membros da comunidade que incluem: moradores, proprietário de restaurante, líder comunitário, presidente da Associação de Ceramistas, produtora visual do grupo de dança local, com posterior transcrição para a análise de discurso, além do registro fotográfico e da observação participante, que subsidiaram a análise da Matriz de Swot.

Quadro 1 - Corpus metodológico da pesquisa, Mato Grosso, 2018

\begin{tabular}{|c|l|l|l|c|}
\hline $\begin{array}{c}\text { OBJETIVO } \\
\text { GERAL }\end{array}$ & \multicolumn{2}{|l|}{$\begin{array}{l}\text { Investigar a potencialidade socioeconômica e ambiental para o desenvolvimento do } \\
\text { Turismo de Base Comunitária na Comunidade de São Gonçalo Beira Rio, em Cuiabá, } \\
\text { Mato Grosso }\end{array}$} \\
\hline ETAPAS & $\begin{array}{l}\text { TIPO DE } \\
\text { DADOS }\end{array}$ & \multicolumn{1}{|c|}{ MÉTODOS } & \multicolumn{1}{|c|}{ INSTRUMENTOS } & \multicolumn{1}{c|}{ CATEGORIAS } \\
\hline $\begin{array}{l}\text { Planejamento } \\
\text { da pesquisa }\end{array}$ & $\begin{array}{l}\text { Dados } \\
\text { secundários }\end{array}$ & $\begin{array}{l}\text { Pesquisa e análise } \\
\text { bibliográfica e } \\
\text { documental }\end{array}$ & $\begin{array}{l}\text { Periódicos, livros, } \\
\text { dissertações, teses e } \\
\text { documentos }\end{array}$ & $\begin{array}{l}\text { Turismo de Base } \\
\text { Comunitária (TBC) } \\
\text { Planejamento } \\
\text { estratégico }\end{array}$ \\
\hline
\end{tabular}




\begin{tabular}{|l|l|l|l|l|}
\hline $\begin{array}{l}\text { Pesquisa } \\
\text { de campo } \\
\text { e coleta de } \\
\text { dados }\end{array}$ & $\begin{array}{l}\text { Dados } \\
\text { primários }\end{array}$ & $\begin{array}{l}\text { Pesquisa descritiva/ } \\
\text { qualitativa } \\
\text { Pesquisa de } \\
\text { campo/observação } \\
\text { participante }\end{array}$ & $\begin{array}{l}\text { Dados primários: } \\
\text { entrevistas } \\
\text { semiestruturadas } \\
\text { Registro fotográfico }\end{array}$ & $\begin{array}{l}\text { Diagnóstico da } \\
\text { comunidade: } \\
\text { pontos fortes/ } \\
\text { fracos e ameaças/ } \\
\text { oportunidades }\end{array}$ \\
\hline $\begin{array}{l}\text { Análise dos } \\
\text { dados }\end{array}$ & $\begin{array}{l}\text { Análise dos } \\
\text { dados }\end{array}$ & $\begin{array}{l}\text { Pesquisa descritiva e } \\
\text { qualitativa }\end{array}$ & $\begin{array}{l}\text { Matriz de Swot } \\
\text { Análise do Discurso } \\
\text { de Foucault (1969) }\end{array}$ & $\begin{array}{l}\text { Demanda de TBC } \\
\text { Atividades culturais }\end{array}$ \\
\hline
\end{tabular}

Fonte: Elaborado pelas autoras (2019).

\section{CARACTERIZAÇÃO DA COMUNIDADE RIBEIRINHA SÃO GONÇALO BEIRA RIO}

O berço de Cuiabá, local de seu surgimento há 299 anos, foi a vila de São Gonçalo Beira Rio, primeiro povoado da região, assim batizado pelos bandeirantes paulistas no século 17. Atualmente a população estimada é de aproximadamente 400 moradores, distribuídos em menos de cem famílias com algum grau de parentesco (CUIABÁ, 2018).

$A$ bandeira de Pascoal Moreira Cabral que andava à procura de índios destinados ao cativeiro, acabou encontrando ouro no Rio Coxipó, onde fundou o Arraial da ForquiIha, no atual distrito do Coxipó do Ouro. Para garantir o direito de posse da área foi lavrada uma ata de fundação, no dia 8 de abril de 1719, na localidade denominada de São Gonçalo Velho, hoje São Gonçalo Beira Rio, que, então, possuía o porto que permitia a comunicação entre as minas e a Capitania São Paulo (MATO GROSSO, 2018).

A comunidade de São Gonçalo Beira Rio (Figura 2) sempre teve papel de destaque na história de Mato Grosso. Localizada à margem esquerda do Rio Cuiabá, a 11 quilômetros do centro da cidade, apresenta certas peculiaridades culturais, com destaque para as festas de santo, a confecção de peças artesanais, além de possuir diversas peixarias, nas quais se comercializa o peixe cru ou na forma de suculentas preparações da gastronomia local (ROMANCINI, 2005; VASCONCELOS, 2015).

Figura 2 - Localização da Comunidade de São Gonçalo Beira Rio, Mato Grosso

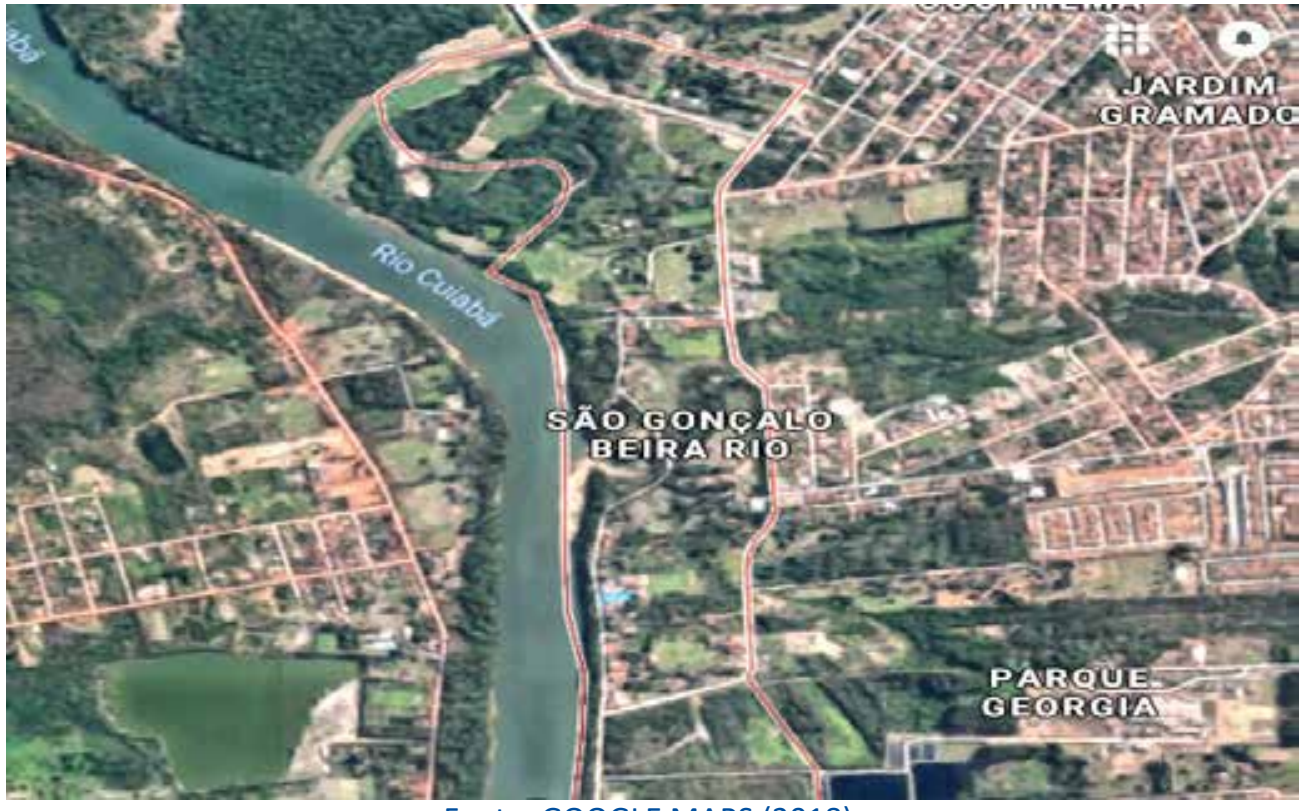

Fonte: GOOGLE MAPS (2018). 
No âmbito da cultura local a presença dos índios Coxiponé ficou refletida nos traços dos moradores de São Gonçalo, nas rimas e músicas, na cerâmica, na pesca, no uso de plantas medicinais, na canoa feita de um tronco de árvore, na benzedeira, nas danças, entre outras tradições cultivadas (ROMANCINI, 2005; MONÇALE; MOREIRA, 2013; MAMEDE et al., 2015; OYAMADA; GATTI, 2016). Destacam-se entre as tradições orais a dança de São Gonçalo, realizada há mais de 50 anos, contribuindo para a memória coletiva da comunidade (SANTOS, 2009).

Para Vasconcelos (2015), não há como falar em cultura cuiabana sem remeter à comunidade São Gonçalo Beira Rio, pois ela está entre os primeiros arraiais de Cuiabá e até hoje preserva a cultura da cidade. Desde início dos anos 2000, de acordo com Romancini (2005) e Santos (2010a, b), a comunidade São Gonçalo Beira Rio representa um grupo participativo na luta por sua identidade cultural, destacando-se que muitos moradores dedicam-se ao artesanato da cerâmica e da viola de cocho, e/ou integrando grupos de cururu e siriri.

Apesar da luta da Comunidade de São Gonçalo Beira Rio, por muito tempo ela foi esquecida pelo poder público, e somente na década de 90 , com a expansão do turismo em Mato Grosso, a localidade recebeu um pouco de infraestrutura (MONÇALE; MOREIRA, 2013). Foi somente com a realização de alguns dos jogos da Copa do Mundo de 2014 em Cuiabá, entretanto, que o governo investiu verdadeiramente em obras de mobilidade urbana na região, como a pavimentação de avenidas e construção de acessos de interligação a outras comunidades (VASCONCELOS, 2015).

Atualmente São Gonçalo Beira Rio faz parte dos roteiros turísticos de Cuiabá, tendo seus atrativos direcionados para contemplação e compras: a gastronomia (peixarias locais), produtos artesanais (cerâmicas de barro), danças e cantos folclóricos (siriri e cururu). $O$ aspecto bucólico e o caráter amistoso da população local, porém, são atrativos que não podem ser desconsiderados nas ações destinadas à promoção e fortalecimento do turismo local, porém o único projeto público identificado, destinado a essa região, é a construção da praça do Marco Zero às margens do Rio Cuiabá, onde se deu a fundação da capital mato-grossense, para a comemoração dos 300 anos da capital do Estado (CUIABÁ, 2018).

\section{Diagnóstico da localidade São Gonçalo Beira Rio: saberes e modos de vida}

Berço de Cuiabá, a comunidade de São Gonçalo Beira Rio conserva uma ampla variedade de tradições, conforme descritas no Quadro 2, que são transmitidas de geração a geração. 
Quadro 2 - Atividades culturais da Comunidade São Gonçalo Beira Rio, Mato Grosso

\begin{tabular}{|c|c|c|c|}
\hline ARTESANATO & $\begin{array}{c}\text { FESTAS TÍPICAS e } \\
\text { RELIGIOSAS }\end{array}$ & GASTRONOMIA & DANÇA \\
\hline $\begin{array}{l}\text { - Confecção de cerâmica em } \\
\text { barro: } \\
\text { *Herança indígena; } \\
\text { *Fonte de renda: comercialização } \\
\text { de souvenirs. } \\
\text { - Confecção viola de cocho': } \\
\text { *Produção artesanal a partir de } \\
\text { madeiras da flora do Pantanal e } \\
\text { Cerrado }\end{array}$ & $\begin{array}{l}\text { - Festas anuais: } \\
\text { *Festa de São } \\
\text { Gonçalo (janeiro) } \\
\text { *Festa do Peixe (abril) } \\
\text { * Festa de São Pedro } \\
\text { (junho) } \\
\text { *Festa das Ceramistas } \\
\text { (setembro) }\end{array}$ & $\begin{array}{l}\text { - Rota do Peixe }{ }^{2}: \\
\text { com } \\
\pm 22 \text { restaurantes } \\
\text { especializados no } \\
\text { preparo de peixes } \\
\text { e pratos regionais }\end{array}$ & $\begin{array}{l}\text { - Cururu }{ }^{3} \text { e Siriri: } \\
\text { danças folclóricas } \\
\text { comuns nas festas de } \\
\text { religiosas, eventos } \\
\text { turísticos, festivais de } \\
\text { cultura popular }\end{array}$ \\
\hline
\end{tabular}

${ }^{1}$ Instrumento musical artesanal em forma de cocho, utilizado no cururu e siriri (IPHAN, 2005; ARIANO, 2017).

${ }^{2}$ Circuito gastronômico do Vale do Rio Cuiabá visando a impulsionar a produção artesanal e industrial da cadeia do peixe.

${ }^{3}$ Dança folclórica de caráter religioso típica da região Centro-Oeste, dançada somente por homens (SANTOS, 2010; OSÓRIO, 2012).

Fonte: Elaboração das autoras (2019).

Apesar do acesso fácil e bem pavimentado a São Gonçalo Beira Rio, a localidade necessita de uma melhor estrutura para acolher a demanda turística. Durante os dias úteis há pouca movimentação de turistas pelas duas alamedas que cortam a comunidade, conforme registro fotográfico na Figura 3; porém aos finais de semana, essas mesmas vias recebem aproximadamente 5 mil transeuntes, que vêm prestigiar as delícias culinárias ofertadas pelas peixarias locais.

Figura 3 - Registro Fotográfico da Comunidade de São Gonçalo Beira Rio, março de 2018

Vias Públicas da Comunidade

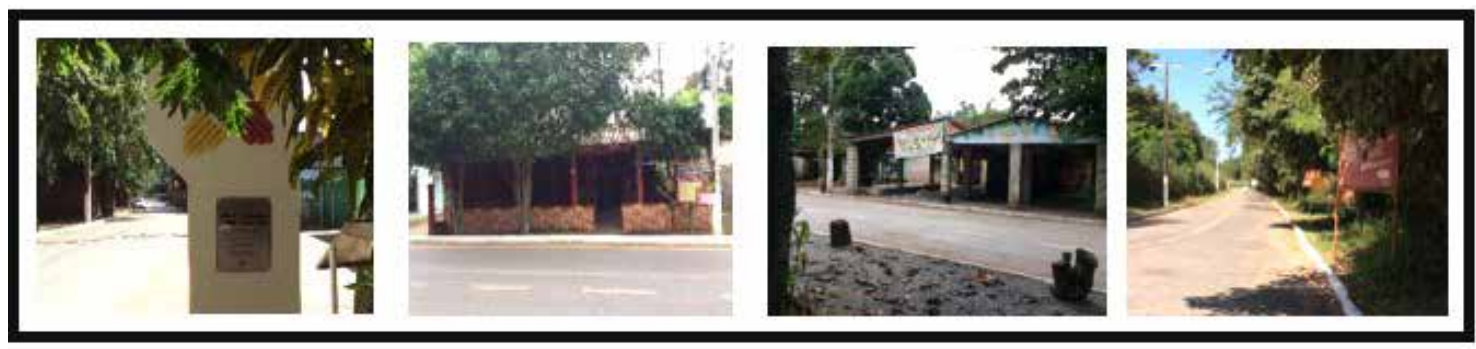

Casa dos Artesãos e Produtos Comercializados

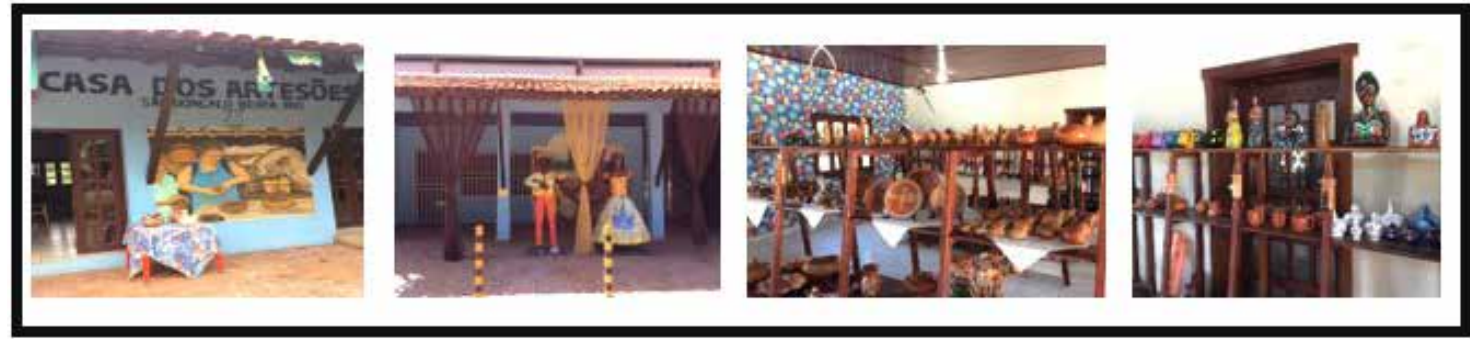

Peixarias (Rota do Peixe São Gonçalo Beira Rio)

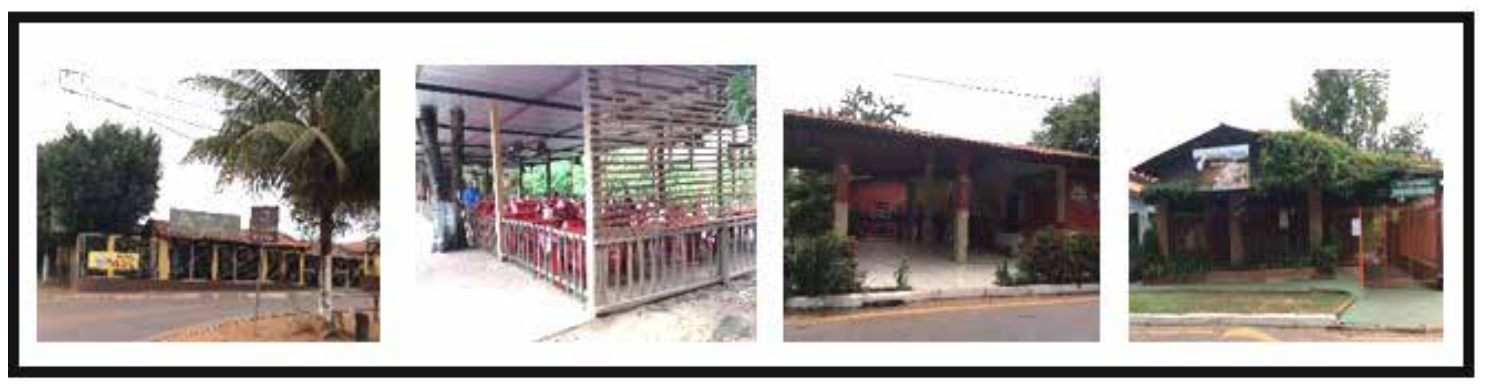


Aspectos Culturais (religiosidade, gastronomia, danças)

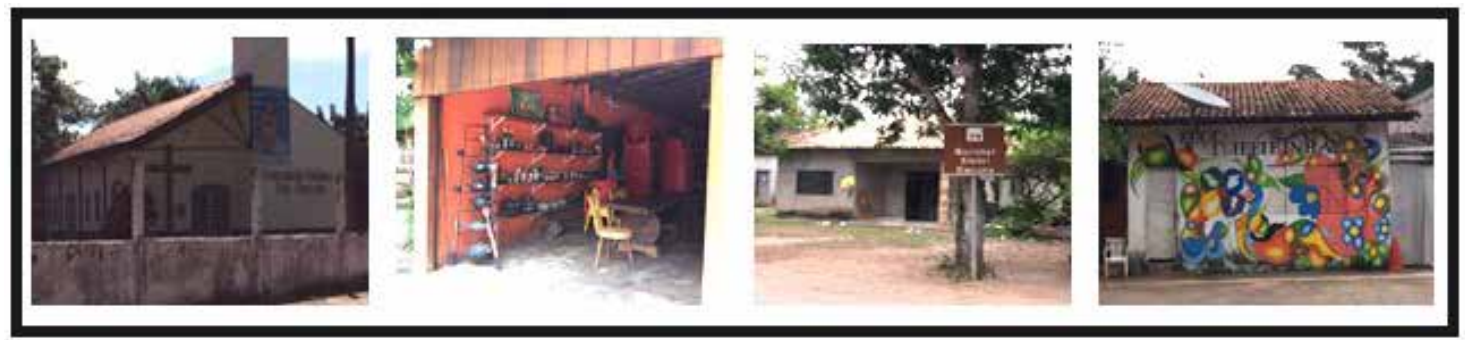

Fonte: Arquivo das autoras.

Os estabelecimentos gastronômicos, em sua maioria adjacentes às próprias residências dos moradores, não apresentam espaço físico para atender toda a demanda. Além disso, há carência de estacionamentos (os automóveis permanecem parados ao longo das vias públicas, próximos às matas que margeiam o Rio Cuiabá); faltam sanitários públicos e locais de espera e lazer para os visitantes; e o transporte urbano público é deficitário (somente 1 linha, com 2 veículos).

A comunidade local reconhece que o poder público (Secretarias Estadual e Municipal de Cultura, Esporte e Turismo) auxiliou no fortalecimento da economia local, com o incentivo à abertura de estabelecimentos especializados em peixes, aproveitando o potencial da comunidade de pescadores e com a inclusão da comunidade na Rota do Peixe (circuito gastronômico formado pelas comunidades ribeirinhas de Bom Sucesso, Pai André, Passagem da Conceição e São Gonçalo, em Cuiabá). Também são bem cônscios de que o povoado, além da culinária, tem outros atrativos que podem servir de chamariz aos turistas, tais como o artesanato em cerâmica, os grupos de dança (siriri e cururu) e as festas tradicionais da comunidade.

Para Appendini e Verduzco (2002, p. 471) "os atores formulam estratégias de ingresso e de vida de acordo com seus recursos (econômicos, forças de trabalho, grau e tipo de conhecimento, educação, capital social e capital cultural)". Ao mesmo tempo, a comunidade preserva saberes e modos de vida, compartilhando sua realidade. Segundo Scopinho, Valencio e Lourenço (2015, p. 139):

Os sujeitos constroem e partilham sentidos sobre a realidade vivida não apenas com a finalidade de interpretá-la, mas também de transformá-la. Tais sentidos expressam as suas identidades sociais e culturais, mas não são abstrações puras porque tanto são gerados quanto se integram às suas experiências e práticas cotidianas, refletindo e constituindo reflexos da estrutura social, da ideologia e da cultura que as sustentam. A relação é de mão dupla e mediada pela atividade do sujeito no mundo, ou seja, o trabalho que ele realiza para produzir e reproduzir a vida.

Neste contexto, utilizou-se para o diagnóstico de TBC a matriz de Swot (Quadro 3), para analisar o cenário por meio dos pontos fortes e fracos, as oportunidades e ameaças identificados. 
Quadro 3 - Análise da matriz de Swot da Comunidade de São Gonçalo Beira Rio, em relação à instituição do Turismo de Base Comunitária, 2018

\begin{tabular}{|c|c|}
\hline PONTOS FORTES & PONTOS FRACOS \\
\hline $\begin{array}{l}\text { - Abundante patrimônio cultural e histórico } \\
\text { - Boa pavimentação das vias de acesso à } \\
\text { comunidade } \\
\text { - Moradores amistosos e acolhedores } \\
\text { - Casa do Artesão bem estruturada } \\
\text { - Grupo de dança Siriri Flor Ribeirinha (conhecido } \\
\text { internacionalmente) } \\
\text { - Gastronomia local bem consolidada } \\
\text { (Rota do Peixe) }\end{array}$ & $\begin{array}{l}\text { - Conflitos de interesses das lideranças } \\
\text { comunitárias } \\
\text { - Falta de projetos coletivos e convergência dos } \\
\text { objetivos comuns } \\
\text { - Abertura sazonal das peixarias (fins de semana e } \\
\text { feriados) } \\
\text { - Ambientes não climatizados } \\
\text { - Baixa qualificação da mão de obra local } \\
\text { - Carência de investimentos em merchandising } \\
\text { (divulgação do destino) }\end{array}$ \\
\hline OPORTUNIDADES & AMEAÇAS \\
\hline $\begin{array}{l}\text { - Incentivo à diversificação da atividade turística: } \\
\text { turismo de experiência } \\
\text { - Abertura de locais de hospedagem } \\
\text { - Ampliação do número de vagas de trabalho } \\
\text { - Festividades e eventos das comemorações do } \\
\text { tricentenário de Cuiabá (em abril de 2019) } \\
\text { - Construção e inauguração da Praça do Marco } \\
\text { Zero (Prefeitura de Cuiabá) } \\
\text { - Estabelecer parcerias com empresas do trade } \\
\text { turístico (agências, hotéis) }\end{array}$ & $\begin{array}{l}\text { - Assoreamento das margens do Rio Cuiabá } \\
\text { - Falta de projeto de conservação e preservação } \\
\text { - Peixarias com infraestrutura deficitária } \\
\text { - Carência de local adequado para estacionamento } \\
\text { de veículos } \\
\text { - Desinteresse dos jovens com a continuidade das } \\
\text { tradições locais } \\
\text { - Ausência de políticas públicas efetivas de } \\
\text { fomento e apoio ao turismo } \\
\text { - Falta de dados estatísticos confiáveis para } \\
\text { subsidiar ações de turismo na localidade }\end{array}$ \\
\hline
\end{tabular}

Fonte: Elaboração das autoras (2019).

A escolha da análise de Swot deu-se por ser uma ferramenta comumente empregada em planejamentos estratégicos, por permitir tanto a análise interna como a externa, por meio dos pontos fortes e fracos, ameaças e oportunidades, ou seja, das variáveis controláveis e das não controláveis, respectivamente (OLIVEIRA, 2010).

A ferramenta Swot, amplamente empregada no Brasil para analisar e/ou avaliar o potencial de atrativos turísticos (DANTAS; MELO, 2008; MELO, 2011; BANZATTO et al., 2012; FAGUNDES; SCHMIDT; CENTURIÃO, 2013; MEDEIROS; NASCIMENTO; PERINOTTO, 2017; COSTA et al., 2018), permite verificar a viabilidade de se organizar uma nova forma de turismo e subsidiar o planejamento estratégico (BANZATO et al., 2012).

\section{RESULTADOS E DISCUSSÕES}

Foram realizadas análises de três dimensões do discurso dos moradores da comunidade de São Gonçalo Beira Rio: i) a percepção do papel do turismo para a comunidade; ii) os atrativos turísticos que a comunidade tem para oferecer e iii) as consequências da atividade turística na comunidade. Também foram analisadas as perspectivas da comunidade com relação ao fomento do turismo para a região de estudo.

A atividade turística, indubitavelmente, tem papel relevante para a comunidade por se tratar da principal fonte de renda e trabalho para os moradores de São Gonçalo. Segundo um professor aposentado, morador há 62 anos: "[...] o turismo melhorou muito a condição econômica das pessoas, aqui era um bairro assim... bastante pobre, hoje já está num nível bem mais elevado por causa do turismo". 
Conforme perfil socioeconômico dos bairros de Cuiabá realizada pelo Instituto de Planejamento e Desenvolvimento Urbano em 2007, a renda média dos responsáveis pelo domicílio é de 7,1 salários mínimos, ressaltando-se que 37,93\% pessoas recebem até 2 salários mínimos; $15,17 \%$ de 2 a 3 salários mínimos, 18,28\% de 3 a 5 salários mínimos, $19,66 \%$ de 5 a 10 salários mínimos, 2,76\% de 10 a 20 salários mínimos e 6,21\% acima de 20 salários mínimos (CUIABÁ, 2007).

Com a redução da comercialização de peixes provenientes do Rio Cuiabá, que por muito tempo foi a principal fonte de renda desses ribeirinhos, a inserção da comunidade na Rota do Peixe em 2006-2007 foi um marco para o "ressurgimento" da região e para evitar o êxodo dos jovens em busca de oportunidade de trabalho. De acordo com um comerciante local, morador há 30 anos", "[...] Rota do Peixe foi um fermento que jogou em São Gonçalo. Antes, isso aqui era morto".

De acordo com relatos coletados, antes da Rota do Peixe havia duas ou três peixarias na localidade, hoje há 22 estabelecimentos em funcionamento, quase que exclusivamente aos fins de semanas e feriados. Durante os dias úteis 4-5 restaurantes abrem suas portas, no horário de almoço, para atender os turistas em busca das tradicionais iguarias da região, situação essa que poderia ser alterada se fossem fomentadas outras atividades, que atraiam turistas à localidade, aliada à gastronomia.

Os residentes da localidade São Gonçalo Beira Rio, mesmo alicerçados economicamente nas peixarias locais, reconhecem que possuem outros atrativos a oferecer aos turistas, sendo lembrado o trabalho em cerâmica e as danças locais (siriri e cururu). Conforme um mecânico aposentado, líder comunitário, morador há 53 anos": "[...] além das peixarias, tem o nosso artesanato, o trabalho que é o mais antigo da comunidade...".

Percebe-se que a comunidade possui um artesanato rico culturalmente, oriundo de uma herança dos povos indígenas da região e transmitido de geração em geração, que pode favorecer a atividade turística de base local, como lembra Maldonado (2009). Esta serviria como um complemento ao progresso econômico e ocupacional, para potencializar e dinamizar a arte em cerâmica, que a comunidade de São Gonçalo Beira desenvolve com imensa mestria. A valorização dos saberes pode ser um instrumento de empoderamento comunitário, mas para tanto faz-se necessária a união e engajamento de todos. Para uma ceramista, moradora há 58 anos: "[...] podemos oferecer para os turistas além das peixarias, além do siriri, do cururu, do Flor Ribeirinha, o nosso artesanato".

De acordo com Lobo (2017), o TBC deve nascer de uma demanda primária da própria comunidade, fruto de um processo gradativo que se inicia com o conhecimento sobre gestão participativa, valorização cultural e afirmação da identidade, essas já percebidas na comunidade na pesquisa de campo. Para a Rede Turisol (2018) o turismo comunitário, além da gestão coletiva é essencial a transparência no uso e destinação dos recursos, sendo necessário que todos se envolvam voluntariamente no processo, pois a comunidade é a proprietária e a beneficiária dos empreendimentos turísticos locais. Para Lobo (2017) a busca pelo envolvimento da maior quantidade possível de pessoas serve como uma estratégia para minimizar os conflitos e diversificar visões sobre a atividade e sua relação com o local. 
$\mathrm{Na}$ instituição do TBC é condição sine qua non o desenvolvimento e fortalecimento da Associação Comunitária, fato não evidenciado ao se constatar, em uma comunidade relativamente pequena, a existência de várias lideranças locais (Associação: das artesãs de cerâmica, das peixarias, de siriri) formais e informais, cada qual com ideias e projetos direcionados a seu segmento cultural.

Aqui começou Cuiabá, aqui é um lugar de uma história linda, habitada pelos índios coxiponês, da qual é minha descendência, porque em nasci e me criei nesta comunidade, entendeu? Aqui era pra ter um grande museu, contando toda a história desta comunidade, com peças que as pessoas daqui têm em casa guardadas, que era pra tá dentro desse museu (Produtora visual, moradora há 41 anos).

[...] estamos tentando ver se a gente desenvolve também, passeios turísticos de barco, mais só que até agora os financiamentos que a gente tem aqui os juros são altíssimos e acaba não compensando pra pessoas que querem tocar (Professor aposentado, morador há 62 anos).

Em prol de atrair maior demanda de turistas, cada subgrupo da comunidade possui ideias de ações que privilegiem o seu segmento; por exemplo, o grupo de pescadores idealiza desenvolver passeio de barco pelo Rio Cuiabá; por outro lado, a associação de artesãs quer comprar maquinários para aumentar a produção e comercialização de cerâmicas, além de reduzir o trabalho pesado, pois as ceramistas são em sua maioria idosas; já a produtora cultural do grupo de dança de grande destaque mundial, originário da comunidade, pensa em criar um museu contando a história da comunidade e da localidade. São ideias de atividades segmentadas, que poderiam ser incorporadas em um projeto único, contemplando toda a comunidade.

A conservação ambiental é outro aspecto lembrado na fala da comunidade, porém pouco observado na prática, pois ao transitar pelas margens do rio avistou-se presença de lixo (garrafas, latas, copos descartáveis), além de assoreamento, provavelmente decorrente do desmatamento.

Já teve até carro que caiu no rio. Sim, sim já teve, já teve. Tem pedaço de asfalto fartando, cê viu, né?" (Ceramista, moradora há 58 anos).

[...] nosso asfalto está desmoronando, está com erosão aqui. Vai esperar o asfalto primeiro acabar pra não ter mais como passar carro para poder vir arrumar? Né? (Produtora visual, moradora há 41 anos).

Atualmente existe apenas um projeto ambiental em andamento na comunidade chamado Balsa Ecológica, que é uma ação da prefeitura, que visa a preservar o Rio Cuiabá e também evitar que os resíduos produzidos pela população cheguem ao Pantanal. Diariamente ela percorre cerca de cinco quilômetros, em um trecho que vai da Ponte Nova até a comunidade de São Gonçalo Beira Rio.

Diante do observado, o TBC pode ser uma saída para a conservação ambiental, pois a atividade procura gerar o menor impacto possível ao meio ambiente. Além disso, é uma alternativa positiva e potencialmente sustentável de desenvolvimento econômico para pequenas comunidades autóctones (como é o caso da localidade de São Gonçalo Beira Rio) na medida em que proporcionaria a manutenção das práticas cotidianas 
locais, a multifuncionalidade dos espaços tradicionais e o incentivo a projetos e ações de conservação ambiental (CORIOLANO; LIMA, 2003; BARTHOLO; SANSOLO; BURSZTYN, 2009; GONÇALVES; SILVA, 2017).

É nítida a percepção de que os moradores comungam de pensamentos similares quanto à importância da atividade turística para a região, e de que a comunidade possui, sem sombra de dúvidas, outros atrativos a serem ofertados:

[...] também tem a cerâmica... arte que é milenar aqui no São Gonçalo (Professor aposentado, morador há 62 anos).

Temos a associação de artesanato aqui no São Gonçalo, então podemos oferecer para os turistas além das peixarias além do cururu, o siriri do Flor Ribeirinha, né?, que é grupo aqui do São Gonçalo, que já foi campeão na Turquia (Ceramista, moradora há 58 anos).

O artesanato local, né? Eles (os turistas) poderiam estar visitando os quintais daqueles que trabalham com artesanato, que também fazem doces... aprender a fazer a cerâmica; podia ter licor pra vender, o doce pra vender também (Produtora visual, moradora 41 anos).

A inciativa de vivência cultural, a que se refere a entrevistada, faz parte de um projeto a ser desenvolvido no "Quintal da Domingas" (sede do grupo Flor Ribeirinha) e tem por objetivo oferecer uma visita guiada à localidade, com explanações sobre a história e gastronomia e práticas de aulas de dança (siriri) e de artesanato em cerâmica. De acordo com a coordenadora visual do grupo, essa demanda surgiu devido ao fato dos turistas demonstrarem curiosidade em conhecer mais o siriri depois da visibilidade internacional alcançada pelos dançarinos.

Evidenciou-se que apesar do potencial nota-se, na comunidade, a falta de convergência de objetivos, de se priorizar ações e o trabalho conjunto, visando ao fortalecimento da atividade turística, reconhecidamente o pilar central da economia local. Ressalta-se que o turismo comunitário requer o envolvimento dos moradores locais, elaborando um processo de planejamento participativo desde as tomadas de decisão até a execução das atividades (LOBO, 2017; PAULA; REZENDE; ALVARES, 2018). Por meio do TBC, Lobo (2017) acredita que a população poderia perceber a força do associativismo e voltaria a participar da vida política da comunidade.

Sugere-se um planejamento realizado em etapas na instituição do TBC, baseado em Guzzatti, Sampaio e Coriolano (2013): a) diagnóstico das características territoriais; b) sensibilização dos moradores sobre os atrativos culturais locais; c) diagnóstico participativo com as artesãs, grupo de danças, moradores, lideranças locais e proprietários das peixarias; d) fortalecimento do associativismo; e) efetivação dos negócios; f) capacitação e g) promoção, podem nortear as ações para a introdução do TBC na localidade de estudo.

Diante do exposto, a organização social pode colaborar para melhorar as condições de vida da comunidade local, fazendo com que a troca de experiências direcionadas a objetivos comuns constituam oportunidades de crescimento e desenvolvimento local e social (BRAMBATTI; NITSCHE, 2018). O desenvolvimento local refere-se não somente ao crescimento econômico, mas também ao desenvolvimento social, ambiental, 
cultural, político e humano (TURISOL, 2018). Todas essas dimensões devem ser integradas, pois não é possível desmembrar a interdependência existente entre elas, mantendo sempre a ênfase no protagonismo da comunidade, princípio básico do TBC.

Após levantamento prévio realizado, percebeu-se que o Turismo de Base Comunitária (TBC) representa uma alternativa ao desenvolvimento para a comunidade local, colocando os atores locais como protagonistas no processo de produção da oferta turística. Ou seja, é necessário pensar o TBC como uma metodologia permeada por processos, etapas e técnicas de estabelecimento que implicam uma conotação prescritiva. Dessa forma, o TBC pode representar tanto um modelo como um meio de empoderamento, proporcionando autonomia para a comunidade para definir e discutir as possibilidades e estratégias de turismo.

\section{CONSIDERAÇÕES FINAIS}

Em razão do objetivo deste estudo, que pretendia investigar os principais desafios e possibilidades para o desenvolvimento do Turismo de Base Comunitária na comunidade ribeirinha São Gonçalo Beira Rio, são feitas algumas considerações que respondem a este questionamento.

Atrair mais turistas à comunidade de São Gonçalo Beira Rio é importante para fortalecer a economia local; porém o estímulo ao crescimento dessa demanda carece de um planejamento prévio, que vise a um maior envolvimento comunitário associado à preservação e conservação ambiental. Desta forma o Turismo de Base Comunitária, mesmo não sendo considerado, por muitos, um segmento e sim uma forma de fazer turismo, pode ser vantajoso, tanto pelos aspectos sociais, pelas trocas culturais entre visitantes e moradores, como pelos aspectos econômicos. Além disso, esse modelo pode ser um caminho alternativo para a melhoria da qualidade de vida e do bem-estar da população receptora.

Sem dúvida o TBC é uma proposta que merece ser colocada em prática segundo demandas e potencialidades da comunidade. Diante das inúmeras variáveis identificadas, faz-se necessário um planejamento participativo dos atores envolvidos, bem como adoção de estratégias comunitárias para que o TBC aconteça de fato.

Identificou-se algumas limitações da pesquisa, como a carência de registros estatísticos sobre turismo na comunidade e a falta de dados e participação dos órgãos públicos nas ações voltadas ao TBC. De outro lado, foram percebidas ações isoladas em prol do Turismo de Base Comunitária na comunidade ribeirinha São Gonçalo Beira Rio em detrimento da coletividade, beneficiando apenas parte da comunidade, necessitando resgatar o espírito de coletividade e cooperação.

Salienta-se que o TBC, apesar de surgir pela demanda da comunidade, depende da parceria e dos arranjos locais com representações locais e agências de fomento como: setor público, Organizações Não Governamentais, consultores, empresas de turismo locais, agentes intermediários de turismo (agências e operadoras turísticas) e evidentemente as próprias comunidades (BUCKLEY, 2003; STRONZA; PEGAS, 2008), consolidando processos de governança ante a dinâmica do TBC. Estas sinergias podem garantir a sustentabilidade do empreendimento, fomentando um desenvolvimento mais sustentável, fortalecendo sentimento de confiança e de identidade cultural. 
Nesse sentido, em virtude da complexidade, desafios, oportunidades e inúmeras variáveis identificadas, percebe-se que não se esgotam as discussões sobre turismo comunitário na localidade de São Gonçalo Beira Rio. Ou seja, trabalhos futuros de TBC devem ser realizados como uma proposta possível para melhor alicerçar a adoção dessa modalidade turística a fim de atingir o tão almejado desenvolvimento socioeconômico e ambiental e consequentemente melhora das condições de vida das pessoas diretamente envolvidas, diante da riqueza de saberes e dos modos de vida desta comunidade, partindo-se de uma metodologia de concepção, elaboração e execução de um projeto participativo de TBC com a comunidade.

\section{REFERÊNCIAS}

ALCANTARA, L. C. S.; FEUSER, S.; SAMPAIO, A. C. C. Turismo de base comunitária: uma experiência na zona de educação para o ecodesenvolvimento do Rio Sagrado (Morretes, Paraná, Brasil). Turismo \& Sociedade, Curitiba, v. 8, n. 2, p. 342-359, maio/ago. 2015.

ALMEIDA, F. A. B.; CASTRO, J. F. Planejamento do turismo de base comunitária: perspectivas críticas. Caderno Virtual de Turismo. Rio de Janeiro, v. 17, n. 3, p. 66-81, dez. 2017.

APPENDINI, K. A.; VERDUZCO, G. La transformación de la ruralidad mexicana: modos de vida y respuestas locales y regionales. Estudios Sociologicos, México, v. XX, n. 59, p. 468-474, 2002.

ARIANO, H. A. Viola de Cocho: controvérsias em torno do registro de propriedade de um símbolo regional. Revista de Antropologia do Centro-Oeste. Cuiabá, v. 4, n. 7, p. 153-171, jan./jul. 2017.

BANZATO, B. M., FAVERO, J. M., AROUCA, J. A. C.; CARBONARI, J. H. B. Análise ambiental de unidades de conservação através dos métodos SWOT e GUT: o caso do parque estadual restinga de Bertioga. Revista Brasileira de Gestão Ambiental, Pombal-PB, v. 6, n. 1, p. 38-49, jan./dez. 2012.

BARRETTO, M. Relações entre visitantes e visitados: um retrospecto dos estudos socioantropológicos. Turismo em Análise, São Paulo, v. 15, n. 2, p. 133-149, 2004.

BARTHOLO, R.; SANSOLO, D. G.; BURSZTYN, I. (org.). Turismo de base comunitária: diversidade de olhares e experiências brasileiras. Rio de Janeiro: Letra e Imagem, 2009. 508 p.

BRAMBATTI, L. E.; NITSCHE, L. B. Roteiros rurais: associativismo e participação comunitária. O roteiro Caminhos de Guajuvira, Araucária-PR. Revista Rosa dos Ventos - Turismo e Hospitalidade, Caixas do Sul, v. 10, n. 1, p. 71-84, jan./mar. 2018. DOI: http://dx.doi.org/10.18226/21789061.

BRASIL. Ministério do Turismo. Dinâmica e diversidade do turismo de base comunitária: desafio para a formulação de política pública. Brasília: Ministério do Turismo, 2010a. 88 p.

BRASIL. Ministério do Turismo. Segmentação do turismo e o mercado. Brasília: Ministério do Turismo, 2010b. 170 p.

BRASIL. Ministério do Turismo. Plano Nacional de Turismo 2018-2022. Brasília: Ministério do Turismo, 2018. 162 p.

BUCKLEY, R. Case studies in ecotourism. Reino Unido: Cabi International; Oxfordshire, 2003.

CORIOLANO, L. N. M. T.; LIMA, L. C. Turismo comunitário e responsabilidade socioambiental. Fortaleza: Eduece, 2003. 366 p.

CORIOLANO, L. N. M. T. O turismo comunitário no nordeste brasileiro. In: BARTHOLO, R.; SANSOLO, D. G.; BURSZTYN, I. (org.). Turismo de base comunitária: diversidade de olhares e experiências brasileiras. Rio de Janeiro: Letra e Imagem, 2009. p. 277-287.

COSTA, S. S.; LEMOS, T. A.; CAMPOS, D. P. F.; OLIVEIRA, J. C.; GUERREIRO, Q. L. M. Análise swot como ferramenta para diagnosticar o potencial turístico da comunidade Ponta de Pedras, Santarém-PA. Revista Ibero-Americana de Ciências Ambientais. Aracaju, v. 9, n. 6, jul. 2018. Edição especial Congaba.

CUIABÁ. Prefeitura de Cuiabá. Perfil socioeconômico dos bairros de Cuiabá. Cuiabá: Instituto de Planejamento e Desenvolvimento Urbano (IPDU), 2007. 124 p.

CUIABÁ. Secretaria Municipal de Cultura, Esporte e Turismo. Portal. 2018. Disponível em: http://www. cuiaba.mt.gov.br/secretarias/secretaria-de-cultura-esporte-e-turismo/13123.

DANTAS, N. G. S.; MELO, R. S. O método de análise SWOT como ferramenta para promover o diagnóstico turístico de um local: o caso do município de Itabaiana-PB. Caderno Virtual de Turismo, Rio de Janeiro, v. 8, n. 1, p. 118-130, 2008. 
ENDLICH, A. M. Perspectivas sobre o urbano e o rural. In: SPOSITO, M. E. B.; WHITACKER, A. M. (org.). Cidade e campo: relações e contradições entre urbano e rural. 2. ed. São Paulo: Expressão Popular, 2010. p. 11-31.

FABRINO, N. H.; NASCIMENTO, E. P.; COSTA, H. A. Turismo de base comunitária: uma reflexão sobre seus conceitos e práticas. Caderno Virtual de Turismo, Rio de Janeiro, v. 16, n. 3, p. 172-190, dez. 2016.

FAGUNDES, M. B. B.; SCHMIDT, V.; CENTURIÃO, D. A. S. Identificação das variáveis de SWOT como ferramenta para promover o diagnóstico turístico e o desenvolvimento local: Corumbá, MS. Informe Gepec, Toledo, v. 17, n. 1, p. 6-22, jan./jun. 2013.

FOUCAULT, M. A arqueologia do saber. Rio de Janeiro: Forense Universitária, 1969.

FREIRE, L. S.; FERREIRA, H. C. H. O turismo de base comunitária como alternativa de desenvolvimento local: o caso de Curuçá-Pará. Revista Associação Brasileira dos Estudos do Trabalho, Juiz de Fora, v. 5, n. 3, p. 36-44, set./dez. 2015.

GABRIELL, C. P.; SANTOS, G. N. Turismo de base comunitária e patrimônio cultural imaterial no Nordeste Brasileiro. Caderno Virtual de Turismo, Rio de Janeiro, v. 16, n. 3, p. 141-154, dez. 2016.

GÓMEZ, C. P.; FALCÃO, M. C.; CHEREM, L.; SILVA, T. N. A participação da comunidade no turismo de base comunitária: um estudo de múltiplos casos. Caderno Virtual de Turismo. Rio de Janeiro, v. 16, n. 2, p. 263279, ago. 2016.

GONÇALVES, S.; SILVA, G. C. J. Possibilidades do turismo comunitário na reserva de desenvolvimento sustentável Ponta do Tubarão/RN. Caderno Virtual de Turismo, Rio de Janeiro, v. 17, n. 3, p. 82-95, dez. 2017. GRIMM, I. J.; ALCÂNTARA, L. C. S.; SAMPAIO, C. A. C. Tourism under climate change scenarios: impacts, possibilities, and challenges. Revista Brasileira de Pesquisa em Turismo, São Paulo, 12(3), p 1-22, set./ dez. 2018. Disponível em: https://www.rbtur.org.br/rbtur/article/view/1354/823. DOI: http://dx.doi. org/10.7784/rbtur.v12i3.1354.

GUZZATTI, T. C.; SAMPAIO, C. A. C.; CORIOLANO, L. N. M. T. Turismo de base comunitária em territórios rurais: caso da Associação de Agroturismo Acolhida na Colônia (SC). Revista Brasileira de Ecoturismo, São Paulo, v. 6, n. 1, p. 93-106, jan./abr. 2013.

HALLACK, N.; BURGOS, A.; CARNEIRO, D. M. R. Turismo de base comunitária: estado da arte e experiências brasileiras. AmbientalMente Sustentable, España, v. 1, n. 11-12, p. 7-25, enero/dec. 2011.

IBGE. Instituto Brasileiro de Geografia e Estatística. Classificação e caracterização dos espaços rurais e urbanos do Brasil: uma primeira aproximação. Coordenação de Geografia. Rio de Janeiro: IBGE, 2017. 84 p. IPHAN. Instituto do Patrimônio Histórico e Artístico Nacional. Dossiê IPHAN 8: modo de fazer viola de Cocho. Brasília: IPHAN, 2005. 116 p.

KRIPPENDORF, J. Sociologia do turismo: para uma nova compreensão do lazer e das viagens. São Paulo: Aleph, 2000. $186 \mathrm{p}$.

LOBO, P. N. M. O turismo comunitário como desafio ao desenvolvimento sustentável: o caso da Resex do Batoque, Aquiraz/CE. Caderno Virtual de Turismo, Rio de Janeiro, v. 17, n. 2, p. 25-41, ago. 2017.

MALDONADO, C. O turismo rural comunitário na América Latina: gênesis, características e políticas. In: BARTHOLO, R.; SANSOLO, D. G.; BURSZTYN, I. (org.). Turismo de base comunitária: experiências brasileiras. Rio de Janeiro: Letra e imagem, 2009. 30-31 p.

MAMEDE, J. S. S.; DAVID, M.; TSUKAMOTO FILHO, A. A.; PASA, M. C. Os quintais e manifestações culturais da comunidade São Gonçalo Beira Rio, Cuiabá-MT. Biodiversidade, Rondonópolis, MT, v. 14, n. 1, p. 168$182,2015$.

MATO GROSSO. Lei no 10.183, de 18 de novembro de 2014. Dispõe sobre a Política Estadual do Turismo e dá outras providências. Diário Oficial do Estado, 18 de novembro de 2014. Disponível em: https://www. al.mt.gov.br/legislacao/12254/visualizar. Acesso em: 24 jun. 2018.

MATO GROSSO. Artesanato de Mato Grosso. 2018. Disponível em: http://www.sedec.mt.gov. $\mathrm{br} /-/ 3027075$-artesanato?inheritRedirect=true.

MEDEIROS, J. L.; NASCIMENTO, M. A. L.; PERINOTTO, A. R. C. Análise SWOT e turismo: uma avaliação estratégica no Projeto Geoparque Seridó/RN. Ciência e Sustentabilidade. Juazeiro do Norte, v. 3, n. 1, p. 94-123, jan./jun. 2017.

MELO, N. R. A aplicação da análise SWOT no planejamento turístico de uma localidade: o caso de Araxá-MG. Caderno Virtual de Turismo, Rio de Janeiro, v. 11, n. 2, p. 164-176, ago. 2011.

MESQUITA, J. L. Turismo de aventura e ecoturismo sustentável: diferenças. Estadão, 18 ago. 2014. Disponível em: https://marsemfim.com.br/diferenca-entre-turismo-de-aventura-ecoturismo-e-turismo-sustentavel/\#: :text=Ecoturismo\%20(ou\%20turismo\%20ecol\%C3\%B3gico),a\%20consci\%C3\%AAncia\%20ambiental\%20nos\%20turistas. Acesso em: 16 jul. 2020. 
MIELKE, E. J.; PEGAS, F. Turismo de base comunitária no Brasil. Insustentabilidade é uma questão de gestão. Revista Turismo em Análise, v. 24, n. 1, p. 170-189, abr. 2013.

MONÇALE, A. M.; MOREIRA, B. D. Fotografia, etnografia e festa: um olhar sobre a festa de santo na comunidade São Gonçalo Beira Rio - Cuiabá/MT. CONGRESSO DE CIÊNCIAS DA COMUNICAÇÃO NA REGIÃO CENTRO-OESTE, 15., 2013, Rio Verde, GO, 30/5 a 1ㅇ6/2013.

MORAES, W. V.; EMMENDOERFER, M. L. Turismo comunitário e inclusão social: análise do roteiro turístico de base comunitária do projeto boas práticas na Serra do Brigadeiro - MG. Abet, Juiz de Fora, v. 5, n. 3, p. 26-35, set./dez. 2015.

OLIVEIRA, D. P. R. Planejamento estratégico. 28. ed. São Paulo: Atlas, 2010. 335 p.

OLIVEIRA, R. S.; CORDEIRO, J. S. Análise dos atrativos naturais da Serra dos Alves, Senhora do Carmo, Itabira, MG, Brasil: uma contribuição para o desenvolvimento do turismo sustentável. Revista Turismo em Análise, São Paulo, v. 28, n. 2, p. 206-223, maio/ago. 2017.

OLIVEIRA, M.; FREITAS, H. Focus Group: instrumentalizando o seu planejamento. In: GODOI, C. K.; BANDEIRADE-MELLO, R.; SILVA, A. B. da (org.). Pesquisa qualitativa em estudos organizacionais: paradigmas, estratégias e métodos. São Paulo: Saraiva, 2006.

OSORIO, P. S. Os festivais de cururu e siriri. Anuário Antropológico, Brasília, n. 1, p. 237-260, 2012.

OYARZÚN, E. M.; CARCAMO, C. G. (org.). Analisis de la red agroturismo Chiloé. Valdivia, Los Ríos, Chile: Instituto de Turismo; Universidad Austral de Chile, 2001.

OYMADA, G. C.; GATTI, F. Arte e identidade de gênero na Comunidade São Gonçalo Beira Rio em Cuiabá-MT. Revista de Administração do Sul do Pará. Pará, v. 3, n. 1, p-53-64, jan./abr. 2016.

PAULA, L. B.; REZENDE, A. C.; ALVARES, D. F. Planejamento e gestão de destinos turísticos a partir do fortalecimento e engajamento das partes interessadas. Revista de Cultura e Turismo, Ilhéus, BA, v. 12, n. 1, p. 31-58, fev. 2018.

PEZZI, E.; VIANNA, S. L. G. A experiência turística e o turismo de experiência: um estudo sobre as dimensões da experiência memorável. Revista Turismo em Análise, São Paulo, v. 26, n. 1, 2015. Especial.

ROMANCINI, S. R. Paisagem e simbolismo no arraial pioneiro São Gonçalo em Cuiabá-MT. Espaço e Cultura, Rio de Janeiro, n. 19-20, p. 81-87, jan./dez. 2005.

SAMPAIO, C. A. C.; ZECHNER, T.; HENRIQUEZ, C.; CORIOLANO, L. N. M.; FERNANDES, S. Turismo comunitário a partir de experiências brasileiras, chilenas e costarriquenha. Revista Brasileira de Pesquisa em Turismo, São Paulo, v. 8, n. 1, p. 42-58, jan./mar. 2014. Obtido em: https://rbtur.org.br/rbtur/article/ view/575/628. DOI: https://doi.org/10.7784/rbtur.v8i1.575.

SANTOS, G. Cultura popular e tradição oral na festa de São Gonçalo Beira Rio. ENECULT - ENCONTRO DE ESTUDOS MULTIDISCIPLINARES EM CULTURA, 5., 2009, Salvador, Bahia, Brasil: Faculdade de Comunicação/Ufba, 27 a 29 maio 2009.

SANTOS, G. L. S. O siriri na contemporaneidade em Mato Grosso: suas relações e trocas. 2010. Dissertação (Mestrado) - Universidade Federal de Mato Grosso, Instituto de Linguagens, Programa de Pós-Graduação em Estudos de Cultura Contemporânea, 2010a.

SANTOS, G. L. S. Reflexões sobre a dança siriri e processos identitários em Cuiabá-MT. ENCONTRO DE ESTUDOS MULTIDISCIPLINARES EM CULTURA, 6., 2010, Salvador-BH, 25-27 maio 2010b.

SCOPINHO, R. A.; VALENCIO, N. F. L. S.; LOURENÇO, L. F. Memória, cotidiano e trabalho: notas sobre modos de vida e subjetividades na Serra do Açor, Portugal. Novos Cadernos NAEA, v. 18, n. 2, p. 135-148, jun./set. 2015.

SILVA, F. P. S.; MATTA, A. E. R.; SÁ, N. S. C. Turismo de base comunitária no antigo Quilombo Cabula. Caderno Virtual do Turismo, Rio de Janeiro, v. 16, n. 2, p.79-92, ago. 2016.

STRONZA, A.; GORDILLO, J. Community Views of Ecotourism: Redefining Benefits. Annals of Tourism Research, v. 35, v. 2, p. 444-468, 2008.

STRONZA, A., PEGAS, F. Ecotourism and Conservation: Two Cases from Peru and Brazil. Human Dimensions of Wildlife, 13 (4), p. 263-279, 2008. DOI: 10.1080/10871200802187097

TURNER, Victor W.; BRUNER, Edward M. (ed.). Dewey, Dilthey, and Drama: An Essay in the Anthropology of Experience, Anthropology of Experience. Urbana and Chicago. Illinois, EUA: University of Illinois Press, 1986. p. 33-44.

TURISOL. Rede Brasileira de Turismo Solidário e Comunitário. Projeto Bagagem: semeando o turismo comunitário pelo Brasil. 2018. Disponível em: http://projetobagagem1.tempsite.ws/arquivos/livreto-projeto_bagagem-09-parte1.pdf.

VASCONCELOS, L. C. S. O Bairro São Gonçalo Beira Rio e a Copa do Mundo 2014 em Cuiabá-MT. GeoSaberes, Fortaleza, v. 6, n. 2, p. 376-386, nov. 2015, Especial. 
WEAVER, D. B.; LAWTON, L. J. Twenty years on: the state of contemporary ecotourism research. Tourism Management, v. 28, p. 1.168-1.179, 2007.

WTO. World Tourism Organization. Tourism and the sustainable development goals - good practices in the Americas.. Madri: UNWTO, 2018. p. 56.

ZAPPELLINI, M. B.; FEUERSCHÜTTE, S. G. O uso da triangulação na pesquisa científica brasileira em administração. Administração Ensino e Pesquisa, Rio de Janeiro, v. 16, n. 2, p. 241-273, abr./maio/jun. 2015. 